\title{
High expression level of miR-1260 family in the peripheral blood of patients with ovarian carcinoma
}

\author{
Arash Adamnejad Ghafour ${ }^{1,2}{ }^{\mathbb{D}}$, Demet Akdeniz Odemis ${ }^{1}$, Seref Bugra Tuncer ${ }^{1}$, Busra Kurt ${ }^{1}$, \\ Mukaddes Avsar Saral ${ }^{3}$, Seda Kilic Erciyas ${ }^{1}$, Ozge Sukruoglu Erdogan ${ }^{1}$, Betul Celik ${ }^{1}$, Pinar Saip ${ }^{4}$ and \\ Hulya Yazici ${ }^{1,5^{*}}$
}

\begin{abstract}
The most common gynecologic cancers detected in women in Turkey are uterine cancer, ovarian cancer, and cervical cancer. These data reported that a mean of 3800 individuals were diagnosed with uterine cancer, 2790 were diagnosed with ovarian cancer, and 1950 were diagnosed with cervical cancer, and 400 individuals were diagnosed with other gynecologic cancers each year in Turkey. A mean of 14.270 individuals were detected to have been diagnosed with gynecologic cancers each year in the United States of America (USA). Ovarian cancer treatment is generally composed of chemotherapy, and surgery. In general, chemotherapy is administered after surgery. The identification of the molecular pathogenesis of ovarian cancer, and discovery of new moleculer biomarkers which facilitate the ovarian cancer treatment are required for an effective ovarian cancer treatment in clinics. miRNAs are reported to be the possible biologic indicators for various cancer types. We aimed to investigate 2 miRNAs which were suggested to have effect in ovarian cancer in our (previous) monozygotic twin study from miR-1260 microRNA family whose association with ovarian cancer yet has not been reported in the literature. We investigated the expression levels of miR-1260a, and miR-1260b miRNAs, in the peripheral blood lymphocytes of 150 familial and sporadic ovarian cancer patients, and of 100 healthy individuals of the control group who were matched for age, sex, and ethnicity with the patient group, and investigated their possible property of being a biologic indicator for ovarian cancer. The expression results of ovarian cancer patients were evaluated by comparison of the results of the control group in the study. The expression levels of miR-1260a, and miR-1260b in ovarian cancer patients were found highly increased compared with the levels in the control group. miR-1260a expression level in ovarian cancer patients was detected to have increased approximately 17 fold compared with the control group, and miR-1260 b expression level in ovarian cancer patients was detected to have increased approximately 33 fold compared with the levels in the control group. The String Analyses showed that the miR-1260a was associated with the ribosomal protein family which was known to be effective in the translation stage of cell and that miR-1260b was associated with CHEK2 protein which was a member of the serine/ threonine-protein kinase family. It should be investigated for larger cohorts in benign ovarian diseases and in different stages of patients receiving ovarian cancer treatment whether these two molecules are a noninvasive biomarker and therapeutic target to be used especially in the early diagnosis and prognosis of ovarian cancer in future.
\end{abstract}

\footnotetext{
*Correspondence: hulyayazici67@gmail.com; hy2188@istanbul.edu.tr; hulyayazici@arel.edu.tr

1 Division of Cancer Genetics, Department of Basic Oncology, Oncology Institute, Istanbul University, Fatih, 34093 Istanbul, Turkey

Full list of author information is available at the end of the article
} permits use, sharing, adaptation, distribution and reproduction in any medium or format, as long as you give appropriate credit to the original author(s) and the source, provide a link to the Creative Commons licence, and indicate if changes were made. The images or other third party material in this article are included in the article's Creative Commons licence, unless indicated otherwise in a credit line to the material. If material is not included in the article's Creative Commons licence and your intended use is not permitted by statutory regulation or exceeds the permitted use, you will need to obtain permission directly from the copyright holder. To view a copy of this licence, visit http://creativecommons.org/licenses/by/4.0/. The Creative Commons Public Domain Dedication waiver (http://creativeco mmons.org/publicdomain/zero/1.0/) applies to the data made available in this article, unless otherwise stated in a credit line to the data. 
Keywords: Familial and Sporadic Ovarian Cancer, miRNA expression, Biomarker

\section{Introduction}

Approximately 22.240 individuals were diagnosed with ovarian cancer in the USA in 2018, and 14.070 were reported to have died of ovarian cancer [1]. Malignant tumors constitute $2.5 \%$ of gynecologic tumors in women. $5 \%$ of women diagnosed with these cancers died of advanced stage disease [2, 3]. Ageadjusted incidence rates have been observed in rates generally higher than 8 in 100.000 in the developed regions of the world including the North America, Central, and East Europe. The rates in South America was 5.8 in 100.000, and the mean rate was 3 in 100.000 in Asia, and Africa [4, 5]. Ovarian cancer biology is different than the hematogenously metastating tumors because the ovarian cancer cells are invased into the peritoneal cavity. Ovarian carcinoma with a treatment rate of $30 \%$ is a fatal disease owing to the compression to the visceral organs of rapidly proliferation of tumors, and to the low chemosensitivity of the cells. Ovarian cancer tumorogenesis proceeds through a gradual mutation period from a gradually growing borderline tumor to a well-differentiated carcinoma (Type I) or through a genetically nonstable high degree serous carcinoma with rapid metastasis (Type II) [3].

Two different molecular sub-classes have recently been differentiated using the genetic changes in different histologic subtypes of ovarian cancer. The first category consists of mucinous borderline ovarian tumors with the potential of low degree serous papillary, endometrioid, and low malignity (type I cancers), and the second category consists of high degree serous carcinomas (type II cancers) [6, 7]. The most common subtype of epithelial ovarian carcinoma of the high-grade serous carcinoma (HGSC) is a different disease than the low grade serous carcinoma (LGSC). HGSC generally develops in advanced age, and the response to chemotherapy is good, however the general prognosis is poorer compared than in the LGSC. On the contrary, LGSC developes in the younger ages, and the prognosis is better [8-11]. Ovarian carcinoma is a disease generated by a series of genetic, and epigenetic changes that cause cell transformation [12]. The meta-analyses showed that the risk of developing ovarian cancer in patients with $B R C A 1$ mutation was cumulatively higher. Accordingly, the cumulative risk of ovarian cancer until the age of 70 was $39-40 \%$ in patients with BRCA1 mutation, and this risk was reported as a mean of $11-70 \%$ in patients with $B R C A 2$ mutation [13].
microRNAs (miRNA) are the noncoding RNAs that were first discovered in 1993 in Caenorbabditis Elegans $[14,15]$. miRNA molecules were also reported to be found in all plant, and animal types [16]. More than 50\% of miRNA genes are known to have presented as multicistronic RNA transcripts, and some were located intragenically in a different gene named as the host gene [17]. Approximately $40 \%$ of intergenic miRNAs are located in the intronic regions of the noncoding transcripts, and $10 \%$ are located in the exonic regions $[18,19]$.

miRNAs were shown to cause functional changes in cancer cells, and therefore had roles in various cancers [20]. miR-1260a was shown to be located on 14q24.3 chromosome region, and this miRNA was upregulated in breast cancer, malignant melanoma, hepatocellular carcinoma, colorectal carcinoma, esophageal squamous cell carcinoma, kidney carcinoma, and gastric cancer [21-28]. Although there was no study in the literature suggesting that miR-1260a was specifically associated with ovarian cancer, miR-1260a was suggested to have possibly been upregulated in ovarian cancer in the assumption after the results of the study investigating that in prostate cancer patients $[27,29]$. In addition, the higher expression level of miR1260a, and miR-1260b was also reported in the serum, and FFPE tissues of prostate cancer (PC) patients, and in prostate cell series [29-31]. A new kit was developed, and used which enabled the investigation in the FFPE tissues of patients for diagnosis and molecular classification of prostate cancer patients in Denmark population with the results of cancer associated miRNA studies [29]. miR-1260b was shown to have been expressed in abnormal levels in various tumors, and in human dendritic cells, and miR-1260b was suggested to have a possible role in the immune reaction of dendritic cells in the literature [32]. The anti-tumor effect of Genistein in prostate cancer cell strains was reported to be performed by the downregulation of miR-1260b which targeted the SRRP1, and SMAD4 genes [33]. miR-1260b expression level was reported to have increased in colorectal carcinomas (CRC), and was upregulated particularly in the infiltrative lymph nodes of CRC patients, and higher miR-1260b expression was shown to be associated with lymph node metastasis, and venous invasion [34]. These results showed that miR-1260b might identify the the early period CRC metastasis, and was associated with poor prognosis, and therefore miR-1260b was suggested to be a possible significant molecular bioindicator in CRC prognosis [34]. 
We investigated the expression levels of miR-1260a, and miR-1260b in the peripheral blood lymphocytes of ovarian cancer patients, and healthy controls in the present study in accordance with the evaluations recently suggesting that miRNAs had biologic indicator, and therapeutic target properties, and due to the lack of a sensitive and noninvasive biologic indicator for utilization in the early diagnosis, treatment and, follow-up of ovarian cancer, and these two molecules were evaluated whether they had noninvasive early biologic indicator properties for ovarian cancer.

\section{Material and method}

\section{Study groups}

The study was approved by the Ethics Board of Istanbul University, Istanbul Faculty of Medicine (Ethics Board approval dated 28.05.2018, and with the ethics board decision no: 01). The peripheral blood samples taken from 150 ovarian cancer patients who presented to Cancer Genetics clinic in Istanbul University, Oncology Institute between 2012, and 2017, and who confirmed the use of the residual material of the routine test for research purpose, and from 100 healthy controls who were matched for age, sex, and ethnicity with the patient group, and with no history of cancer in 3 generation relatives in their family, were used. The blood was drawn after the informed consent form was signed by all participants included in the study. The study was pursued with the materials of 127 patients, and 98 healthy individuals after the quality analyses were performed.

\section{Lymphocyte isolation from peripheral blood}

The peripheral blood lymphocytes were differentiated from other blood components using the Ficoll method. The blood sample diluted in a ratio of 1:1 (v/v) with Phosphate Buffer Solution (PBS) was loaded on $2 \mathrm{~mL}$ FicollHistopaque-1077 (Sigma-Aldrich, USA) using a pipette, and centrifugated for $30 \mathrm{~min}$ at room temperature at $400 \mathrm{Xg}$. The differentiated lymphocytes in the medium phase of the tube after centrifugation procedure were transferred into a clean tube using a pasteur pipette. The differentiated cells were precipitated by centrifugating at room temperature at $400 \mathrm{Xg}$ for $10 \mathrm{~min}$. The supernatant was removed, and $2 \mathrm{~mL}$ PBs was added on the precipitated pellete, and pellete was thawed by pipetting. The thawed cells were distributed in 2 cryotubes $1 \mathrm{~mL}$ in each tube, and then centrifugated at room temperature at $400 \mathrm{Xg}$ for $4 \mathrm{~min}$. Supernantants were removed. The cells precipitated in cryotube were incubated for 1 day at $-80^{\circ} \mathrm{C}$. Then, the cells in the cryotubes were placed in liquid nitrogen storage tank for long term storage.

\section{RNA isolation}

A commercial Quick-RNA MiniPrep Kit [Zymo Research, CA, USA ] protocol was used for isolating RNA from lymphocytes. $300 \mu \mathrm{L}$ RNA Lysis Buffer was added on lymphocytes in accordance with the kit protocol, and was centrifugated at $+4^{\circ} \mathrm{C}$ at $12.000 \mathrm{Xg}$ for 30 sec. The supernatant was tranferred into yellow column collection tubes (Spin Away Filter), and 300 $\mu \mathrm{L}$ 95-100 \% ethanol was added, and the mixture was centrifugated for $30 \mathrm{sec}$ at $+4^{\circ} \mathrm{C}$ at $10.000 \mathrm{Xg}$. The phase at the bottom was transferred into green column collection tubes (ZymoSpin IIICG Column). The preparate was incubated at room temperature for $15 \mathrm{~min}$ after adding $5 \mu \mathrm{L}$ DNase I, and $75 \mu \mathrm{L}$ DNA Digestion Buffer. $400 \mu \mathrm{L}$ RNA Prep Buffer was added on the column, and was centrifugated at $+4^{\circ} \mathrm{C}$ at $12.000 \mathrm{Xg}$ for $30 \mathrm{sec}$. The bottom phase was removed. $700 \mu \mathrm{L}$ RNA Wash Buffer was added on the column, the bottom phase was removed again after centrifugation for $30 \mathrm{sec}$ at $+4^{\circ} \mathrm{C}$ at $12.000 \mathrm{Xg} .400 \mu \mathrm{L}$ RNA Wash Buffer was added on the column for repeating the washing procedure, and was centrifugated for $2 \mathrm{~min}$. at $+4^{\circ} \mathrm{C}$ at $12.000 \mathrm{Xg}$. The RNAse noninvolving column was tranferred into a clean centrifugating tube of $1.5 \mathrm{~mL}$, and $100 \mu \mathrm{L}$ sterilised distilled water with no inclusion of DNAse/RNAse was added, and centrifugated at $+4^{\circ} \mathrm{C}$ at $12.000 \mathrm{Xg}$ for 30 seconds. The obtained RNAs were stored at $-80^{\circ} \mathrm{C}$ in several different tubes after quality controls were performed.

\section{Identification of the quality control, and concentrations of RNA samples}

The quantity analyses, and quality controls of the obtained RNAs were performed using a Nanodrop 2000 Spectrophotometer [Thermo Fisher Scientific, USA]. The purity, and concentration measurement of the extracted RNA was performed by reading the absorbance at A260/ A280 nm wave-lengths after the direct loading of the $1 \mu \mathrm{L}$ stock RNA sample. The RNAs with the absorbance between 1.6-2.0 OD were accepted as appropriate for expreimental procedures.

\section{CDNA synthesis}

RNA samples were dissolved, and then vortexed. RNA with a maximum volume of $1 \mu \mathrm{g}$ templeta RNA, $5 \mu \mathrm{L}$ ID3AL RT Buffer, $1 \mu \mathrm{L}$ ID3AL RT Primer, and $1 \mu \mathrm{L}$ ID3AL RT (Reverse Transcriptase) were respectively added in the tube for CDNA reaction. The volume of the obtained mixture was completed to $20 \mu \mathrm{L}$ with distilled water. Pipetaging was performed using a micropipete, and then vortexed. The cDNA forming procedure was completed using a BioRad PCR device with incubation for $30 \mathrm{~min}$ at $42^{\circ} \mathrm{C}$, and for $5 \mathrm{~min}$ at $95^{\circ} \mathrm{C}$. 
Real time qPCR reaction, and measurement of CT value The obtained cDNAs were diluted using sterilised DNA/ RNAse free distilled water with a ratio of $1: 10(\mathrm{v}: \mathrm{v})$. The diluted cDNAs were stored at $-20^{\circ} \mathrm{C} .5 \mu \mathrm{L}$ diluted cDNA, $10 \mu \mathrm{L}$ ID3AL qPCR Master Mix, $2 \mu \mathrm{L}$ ID3AL qPCR assays, and $3 \mu \mathrm{L}$ distilled water were added to obtain a total volume of $20 \mu \mathrm{L}$ for real time qPCR reaction Pipetaging was performed using a micropipete, and inserted on Mic qPCR Cycler (Bio Molecular Systems, Australia) device after vortexing. All qPCR reactions were performed in duplicated manner. The quantitative PCR reactions were performed in duplicated manner. The quantitative PCR procedure was performed in 40 cycles with incubation at $95^{\circ} \mathrm{C}$ for $10 \mathrm{~min}$, and then at $40^{\circ} \mathrm{C}$ for $5 \mathrm{~min}$, then at $95^{\circ} \mathrm{C}$ for $40 \mathrm{sec}$, and at $60^{\circ} \mathrm{C}$ for $30 \mathrm{sec}$. The measurement of the reactions, and calculations were performed using the Mic qPCR software on the device. The miRNA expression levels investigated with this software were calculated quantitatively using the below formula [35].

$$
\begin{aligned}
& \Delta \mathrm{CT}=\mathrm{CT}(\text { Target Gene })-\mathrm{CT} \text { (Reference Gene). } \\
& \Delta \Delta \mathrm{CT}=\Delta \mathrm{CT} \text { (Target Gene) }-\sum \Delta \mathrm{CT} \text { (Reference Gene). }
\end{aligned}
$$

As $\Delta \Delta$ Ct value of 0 , and $2^{0}=1$, the reference value was taken as 1 .

\section{Statistical analyses}

The associations, and evaluations of the miRNA-1260 expression levels of patients, and healthy controls, and the clinical parameters were performed using the $X^{2}$ tests (Yates, Fisher's exact) SPSS.21 statistical program, ANOVA test, and String Analysis. The Kaplan-Meier Analysis was used for identifying whether the expression levels of miR-1260a, and miR-1260b were tha variables affecting the survival; and the ROC analysis was performed for demonstrating the diagnostic performance of the candidate bioindicators miR-1260a, and miR-1260b molecules. The Spearman's correlation test was used for identifying the possible linear association between Ca-125 level of ovarian cancer patients, and the miRNA expression levels.

\section{Results}

The samples of 150 patients diagnosed with ovarian cancer, and 100 healthy controls were used in the study. The study was pursued with 127 patients, and 98 healthy controls after quality control analysis. The mean age of the ovarian cancer patient group was $50 \pm 10$ years $(25-84 y)$, and the mean age of the control group was $48 \pm 11$ years (23-84y). 103 ovarian cancer patients were only diagnosed with ovarian cancer, 16 were diagnosed with an additional breast cancer, 2 were diagnosed with an additional endometrium cancer, and 6 were diagnosed with a different secondary cancer than the cancers described above.

The normality estimation of the groups which was evaluated within the scope of the research using the SPSS v21.0 program was performed using the Kolmogorov-Smirnov test. The normality distribution of the data for miR-1260a was (Kolmogorov-Smirnov $\mathrm{Z}=5,274$; $\mathrm{p}<0.05$ ); and for miR-1260b (Kolmogorov-Smirnov $\mathrm{Z}=5,361 ; \mathrm{p}<0.05$. We used the post-hoc ANOVA test in the resolution of the data because the groups showed a normal distribution, and were investigated in 5 groups. The calculations performed based on the $2^{-\Delta \Delta \mathrm{Ct}}$ values of the patient, and control groups with the evaluations using the ANOVA test showed that the miR-1260a, and miR-1260b expression levels were statistically significant in patient groups compared with the levels in the control groups (p:0.000). We performed the PostHoc Tukey HSD test for detailed demonstration of the significance between the subgroups. The results of this test showed that there was a statistically significant difference for both miRNAs between the healthy controls, and in the patient groups with ovarian cancer, ovarian and breast cancer, ovarian and endometrium cancer, and ovarian and other cancer patients (p:0.000) (Table 1).

The comparison of the miR-1260a expression levels of the healthy control group, and ovarian cancer patients showed that in general miR-1260a expression level was 18.46 fold higher in all patients compared with the levels in healthy women. miR-1260a expression was found as 17.16 fold higher in patients diagnosed with only ovarian cancer, as 16.1 fold higher in patients with two primary cancers as ovarian and breast cancer, the values were increased in 24.68 fold in patients diagnosed with both ovarian and endometrium cancer, and as 40.08 fold in patients diagnosed with a different additional secondary cancer than above with ovarian cancer (Fig. 1).

The comparison of miR-1260b between healthy control group and ovarian cancer groups showed that in general miR-1260b expression level was 31.29 fold in all patients compared with the levels in healthy women. miR-1260b expression was found to have increased in 32.68 fold in patients with only ovarian cancer, and as 19.77 fold in patients with two primary cancers as ovarian and breast cancers, and as 16.23 fold in patients with ovarian and endometrium cancers, and 43.21 fold increase was detected in ovarian cancer patients with a different additional secondary cancer (Fig. 2).

The evaluation of all ovarian cancer patients showed that miR-1260a expression was decreased in $34.7 \%$ $(44 / 127)$ of patients, and was increased in $65.3 \%(83 / 127)$ 
Table 1 ANOVA test results

\begin{tabular}{|c|c|c|c|c|c|c|c|}
\hline $\begin{array}{l}\text { Dependent } \\
\text { Variable }\end{array}$ & Group 1 & Group 2 & Mean Difference & Standard Error & p Value & \multicolumn{2}{|c|}{$\begin{array}{l}\% 95 \\
\text { Confidence } \\
\text { Interval } \\
\text { Lower limit } \\
\text { Upper limit }\end{array}$} \\
\hline \multicolumn{8}{|l|}{ miR-1260a } \\
\hline & Control Group & All Ovarian Cancer & & & $.000^{*}$ & & \\
\hline & & Ovarian + Breast Cancers & $1.37500^{*}$ & .09612 & $.000^{*}$ & 1.1106 & 1.6394 \\
\hline & & Only Ovarian Cancer & $1.35922^{*}$ & .05031 & $.000^{*}$ & 1.2209 & 1.4976 \\
\hline & & Ovarian + Endometrium Cancer & $1.50000^{*}$ & .25464 & $.000^{*}$ & .7996 & 2.2004 \\
\hline & & Ovarian + Other Cancers & $1.00000^{*}$ & .14993 & $.000^{*}$ & .5876 & 1.4124 \\
\hline \multicolumn{8}{|l|}{ miR-1260b } \\
\hline & Control Group & All Ovarian Cancer & & & $.000^{*}$ & & \\
\hline & & Ovarian+ Breast Cancers & $125000^{*}$ & .08968 & $.000^{*}$ & 1.0033 & 1.4967 \\
\hline & & Only Ovarian Cancer & $1.28155^{*}$ & .04693 & $.000^{*}$ & 1.1525 & 1.4106 \\
\hline & & Ovarian + Endometrium & $1.50000^{*}$ & .23756 & $.000^{*}$ & .8466 & 2.1534 \\
\hline & & Ovarian + Other Cancers & $1.00000^{*}$ & .13987 & $.000^{*}$ & .6153 & 1.3847 \\
\hline
\end{tabular}

*; statistically significant $(p<0.05)$

miR-1260a

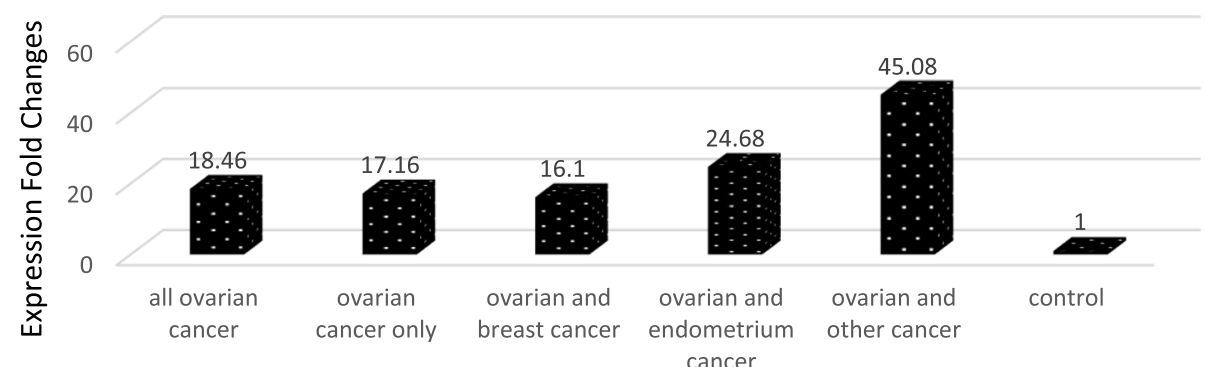

Fig. 1 Graphic Representation of Proportional Differences of miR-1260a Expression in all Patients with Ovarian Carcinoma and Subgroups According to Healthy Controls

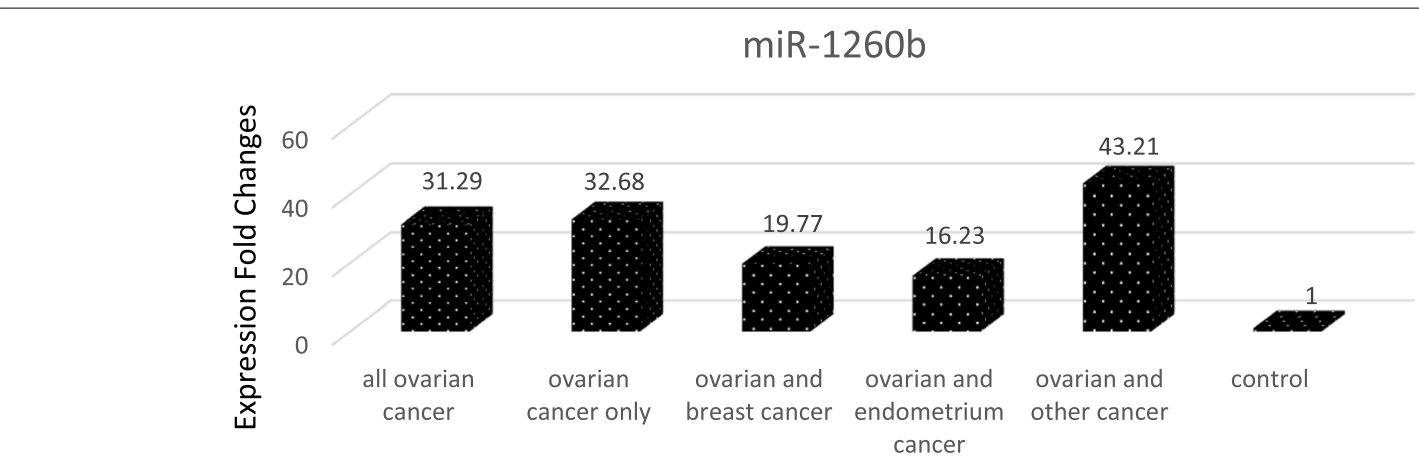

Fig. 2 Graphic Representation of Proportional Differences of miR-1260b Expression in Total Patients with ovarian carcinoma and Subgroups According to Healthy Controls 
Table 2 Distribution of miR-1260a, and miR-1260b expression levels in patients with ovarian cancer

\begin{tabular}{|c|c|c|c|c|c|c|}
\hline \multirow[t]{2}{*}{ Diagnosis } & \multicolumn{2}{|c|}{ miR-1260a Expression } & \multirow{2}{*}{$\begin{array}{l}\text { Total } \\
\text { Total } \\
\text { n (\%) }\end{array}$} & \multicolumn{2}{|c|}{ miR-1260b Expression } & \multirow{2}{*}{$\begin{array}{l}\text { Total } \\
\text { Total } \\
\text { n (\%) }\end{array}$} \\
\hline & $\begin{array}{l}\text { Increased } \\
\mathrm{n}(\%)\end{array}$ & $\begin{array}{l}\text { Decreased } \\
\mathrm{n}(\%)\end{array}$ & & $\begin{array}{l}\text { Increased } \\
\mathrm{n}(\%)\end{array}$ & $\begin{array}{l}\text { Decreased } \\
\mathrm{n}(\%)\end{array}$ & \\
\hline Patients with Only Ovarian Cancer & $66(64.1 \%)$ & $37(35.9 \%)$ & 103(81.1\%) & $74(71.8 \%)$ & $29(28.2 \%)$ & $103(81.1 \%)$ \\
\hline Patients Diagnosed With both Ovarian and Breast Cancer & $10(62.5 \%)$ & $6(37.5 \%)$ & $16(12.6 \%)$ & $12(75.0 \%)$ & $4(25.0 \%)$ & $16(12.6 \%)$ \\
\hline Patients with both Ovarian and Endometrial Cancer & $1(50.0 \%)$ & $1(50.0 \%)$ & $2(1.6 \%)$ & $1(50.0 \%)$ & $1(50.0 \%)$ & $2(1.6 \%)$ \\
\hline Patients with Ovarian and Other Cancers & $6(100.0 \%)$ & $0(00.0 \%)$ & $6(4.7 \%)$ & $6(100.0 \%)$ & $0(0.0 \%)$ & $6(4.7 \%)$ \\
\hline Total n (\%) & $83(65.3 \%)$ & $44(34.7 \%)$ & 127 & $93(73.2 \%)$ & $34(26.8 \%)$ & 127 \\
\hline
\end{tabular}

of patients, however, miR-1260b expression was lower in $26.8 \%(34 / 127)$ of patients, and was increased in $73.2 \%$ $(93 / 127)$ of patients (Table 2$)$.

miR-1260a expression was increased in $64.1 \%(66 / 103)$ of 103 patients diagnosed with only ovarian cancer out of the total of 127 ovarian cancer patients, and was decreased in $35.9 \%(37 / 103)$ of the patients. miR-1260a expression levels of 16 patients diagnosed with both ovarian, and breast cancer were found to have increased in $62.5 \%(10 / 16)$, and was found to have decreased in $37.5 \%(6 / 16)$ of the patients. miR-1260a expression was increased in $50 \%(1 / 2)$, and was decreased in $50 \%$ of patients diagnosed with different primary cancers as ovarian, and endometrium cancer. miR-1260a expression was detected to have increased in $100 \%(6 / 6)$ of patients diagnosed with ovarian cancer, and another secondary cancer different than the above reported cancers (Table 2).

miR-1260b expression was increased in $71.8 \%$ (74/103), and was decreased in $28.2 \%(29 / 103)$ in 103 patients with only ovarian cancer out of 127 ovarian cancer patients. miR-1260b expression levels were found to have increased in $75 \%(12 / 16)$, and was decreased in $25 \%$ $(4 / 16)$ of patients with both ovarian, and breast cancer. miR-1260b expression was increased in 50\%, and was decreased in $50 \%$ of patients with ovarian, and endometrium cancer. miR-1260b expression was detected to have increased in all ovarian cancer patients with an additional secondary cancer (Table 2).

\section{Comparison of the miR-1260a, and miR-1260b Expression Levels with the Clinical Characteristics}

The investigation of the distribution of miR-1260a, and miR-1260b expression levels in different clinical stages of ovarian cancer patients showed that miR-1260a expression level was decreased in $30.5 \%(11 / 36)$, and was increased in $69.5 \%(25 / 36)$ in Stage I/II patients. miR1260a expression level was found lower in 36.3\% (33/91), and was higher in $63.7 \%(58 / 91)$ of ovarian cancer patients in Stage III/IV. However, miR-1260b expression level was found to have decreased in $25 \%$ (9/36), and was increased in $75 \%(27 / 36)$ of patients in Stage I/II, and the expression level was found lower in $27.5 \%$ (25/91), and was found to have increased in $72.5 \%(66 / 91)$ of patients in Stage III /IV (Table 3).

The evaluation of the expression level of ovarian cancer patients in accordance with the pathologic grade showed that miR-1260a expression was decreased in 50\% (11/22), and was increased in $50 \%(11 / 22)$ of patients with pathologic Grade I. The miR-1260a expression level was decreased in $26.3 \%(5 / 19)$, and was increased in $73.7 \%$ $(14 / 19)$ in patients with pathologic grade II. miR-1260a expression level was decreased in 32.5\% (28/86), and was increased in $67.5 \%(58 / 86)$ of patients with pathologic grade III. miR-1260b expression was decreased in $27.3 \%$ $(6 / 22)$, and was increased in $72.7 \%(16 / 22)$ of patients with pathologic grade I. miR-1260b expression level was decreased in $26.3 \%(5 / 19)$, and was increased in $73.7 \%$ $(14 / 19)$ patients with pathologic grade II. miR-1260b expression level was decreased in $26.7 \%$ (23/86), and was increased in $73.3 \%(63 / 86)$ of patients with pathologic Grade III (Table 3).

The evaluation of ovarian cancer in accordance with the histologic grade showed that miR-1260a expression level was increased in 52\% (13/25), and was decreased in $48 \%$ $(12 / 25)$ of patients with histologic Grade I. miR-1260a expression level was increased in $45.8 \%(11 / 24)$, and was decreased in $54.2 \%(13 / 24)$ of patients with histologic Grade II. miR-1260a expression level was increased in $25.6 \%(20 / 78)$, and was decreased in $74.4 \%(58 / 78)$ of patients with histologic Grade III. miR-1260b expression was increased in $36 \%(9 / 25)$, and was decreased in $64 \%(16 / 25)$ of patients with histologic Grade I. miR1260b expression was increased in $29.1 \%(7 / 24)$, and was decreased in $70.9 \%(17 / 24)$ of patients with histologic Grade II. miR-1260b expression was increased in $23 \%$ $(18 / 78)$, and was decreased in $77 \%(60 / 78)$ of patients with histologic Grade III (Table 3).

The evaluation of ovarian cancer patients in accordance with the tumor size showed that miR-1260a expression was increased in $64.3 \%(18 / 28)$, and was decreased in 
Table 3 Comparison of miR-1260a, and miR-1260b expression levels, and the clinical features of patients

\begin{tabular}{|c|c|c|c|c|c|}
\hline \multirow{2}{*}{$\begin{array}{l}\text { Features } \\
\text { Expression Level }\end{array}$} & \multirow{3}{*}{$\begin{array}{l}\text { miR-1260a } \\
\text { Increased } \\
\mathrm{n}(\%)\end{array}$} & \multirow{3}{*}{$\begin{array}{l}\text { Expression } \\
\text { Decreased } \\
n(\%)\end{array}$} & \multirow{3}{*}{$\begin{array}{l}\text { miR-1260b } \\
\text { Increased } \\
\mathrm{n}(\%)\end{array}$} & \multicolumn{2}{|l|}{ Expression } \\
\hline & & & & Decreased & Total \\
\hline & & & & n (\%) & $n(\%)$ \\
\hline \multicolumn{6}{|c|}{ Mean age $50 \pm 10 y(25-84 y)$} \\
\hline $40 y>$ & $11(8.7 \%)$ & $5(3.9 \%)$ & $13(10.2 \%)$ & $3(2.4 \%)$ & $16(12.5 \%)$ \\
\hline $40 y \leq$ & $72(56.7 \%)$ & $39(30.7 \%)$ & $31(24.4 \%)$ & $80(63 \%)$ & $111(87.5 \%)$ \\
\hline Total n (\%) & $83(65.3 \%)$ & $44(34.7 \%)$ & $44(34.7 \%)$ & $83(65.3 \%)$ & 127 \\
\hline \multicolumn{6}{|l|}{ Clinical Stage } \\
\hline Stage 1 & $12(9.4 \%)$ & $10(7.9 \%)$ & $14(11.0 \%)$ & $8(9.3 \%)$ & $22(17.3 \%)$ \\
\hline Stage 2 & $13(10.2 \%)$ & $1(0.8 \%)$ & $13(10.2 \%)$ & $1(0.8 \%)$ & $14(11 \%)$ \\
\hline Stage 3 & $49(38.6 \%)$ & $27(21.3 \%)$ & $56(44.1 \%)$ & $20(15.7 \%)$ & $76(59.9 \%)$ \\
\hline Stage 4 & $9(7.1 \%)$ & $6(4.7 \%)$ & $10(7.9 \%)$ & $5(\% 3.9)$ & $15(11.8 \%)$ \\
\hline Total n(\%) & $83(65.3 \%)$ & $44(34.7 \%)$ & $93(73.2 \%)$ & $34(26.8 \%)$ & 127 \\
\hline \multicolumn{6}{|l|}{ Pathological Grade } \\
\hline Grade 1 & $11(8.7 \%)$ & $11(8.7 \%)$ & $16(12.6 \%)$ & $6(\% 4.7)$ & $22(17.3 \%)$ \\
\hline Grade 2 & $14(11.0 \%)$ & $5(3.9 \%)$ & $14(11.0 \%)$ & $5(3.9 \%)$ & $19(15 \%)$ \\
\hline Grade 3 & $58(45.7 \%)$ & $28(22.0 \%)$ & $63(49.6 \%)$ & $23(18.1 \%)$ & $86(67.7 \%)$ \\
\hline Total n(\%) & $83(65.3 \%)$ & $44(34.6 \%)$ & $93(73.2 \%)$ & $34(26.8 \%)$ & 127 \\
\hline \multicolumn{6}{|l|}{ Histological Grade } \\
\hline Grade 1 & $12(9.4 \%)$ & $13(10.2 \%)$ & $16(12.6 \%)$ & $9(7.1 \%)$ & $25(19.6 \%)$ \\
\hline Grade 2 & $13(10.2 \%)$ & $11(8.7 \%)$ & $17(13.4 \%)$ & $7(\% 5.5)$ & $24(18.9 \%)$ \\
\hline Grade 3 & $58(45.7 \%)$ & $20(15.7 \%)$ & $60(47.2 \%)$ & $18(14.2 \%)$ & $78(61.5 \%)$ \\
\hline Total n(\%) & $83(65.3 \%)$ & $44(34.6 \%)$ & $93(73.2 \%)$ & $34(26.8 \%)$ & 127 \\
\hline \multicolumn{6}{|l|}{ Tumor Size } \\
\hline$<2 \mathrm{~cm}$ & $18(14.2 \%)$ & $10(7.9 \%)$ & $20(15.7 \%)$ & $8(6.3 \%)$ & $28(22 \%)$ \\
\hline$\geq 2 \mathrm{~cm}$ & $65(51.2 \%)$ & $34(26.8 \%)$ & $73(57.5 \%)$ & $26(20.5 \%)$ & $99(78 \%)$ \\
\hline Total n(\%) & $83(65.3 \%)$ & $44(34.6 \%)$ & $93(73.2 \%)$ & $34(26.8 \%)$ & 127 \\
\hline \multicolumn{6}{|l|}{ Treatment } \\
\hline \multicolumn{6}{|l|}{ Surgery } \\
\hline Yes & 78 (63.9\%) & $44(32.1 \%)$ & $87(69.0 \%)$ & $34(27.0 \%)$ & $122(96 \%)$ \\
\hline No & $5(4.0 \%)$ & $0(0.0 \%)$ & $5(4.0 \%)$ & $0(0.0 \%)$ & $5(4 \%)$ \\
\hline Total n(\%) & $83(65.3 \%)$ & $44(34.6 \%)$ & $93(73.2 \%)$ & $34(26.8 \%)$ & 127 \\
\hline \multicolumn{6}{|l|}{ Chemotherapy } \\
\hline Yes & $78(66.1 \%)$ & 40 (25.9\%) & $86(68.3 \%)$ & $30(23.8 \%)$ & $118(92.9 \%)$ \\
\hline No & $5(4.0 \%)$ & $5(4.0 \%)$ & $6(4.8 \%)$ & $4(3.2 \%)$ & $10(7.1 \%)$ \\
\hline Total n(\%) & $83(65.3 \%)$ & $44(34.6 \%)$ & $93(73.2 \%)$ & $34(26.8 \%)$ & 127 \\
\hline \multicolumn{6}{|l|}{ Radiotherapy } \\
\hline Yes & $10(7.9 \%)$ & $5(4.0 \%)$ & $10(7.9 \%)$ & $5(\% 4.0 \%)$ & $15(11.8 \%)$ \\
\hline No & $73(57.4 \%)$ & $39(30.7 \%)$ & $82(65.1 \%)$ & $29(23.0 \%)$ & $112(88.2 \%)$ \\
\hline Total n(\%) & $83(65.3 \%)$ & $44(34.6 \%)$ & $93(73.2 \%)$ & $34(26.8 \%)$ & 127 \\
\hline \multicolumn{6}{|c|}{ Ovarian \& Breast cancer histories in the family } \\
\hline$<2$ persons & $52(40.9 \%)$ & $31(24.4 \%)$ & $59(46.5 \%)$ & $24(\% 18.8 \%)$ & $83(65.3 \%)$ \\
\hline$\geq 2$ persons & $31(24.4 \%)$ & $13(10.3 \%)$ & $34(26.8 \%)$ & $10(7.9 \%)$ & $44(34.7 \%)$ \\
\hline Total n(\%) & $83(65.3 \%)$ & $44(34.7 \%)$ & $93(73.2 \%)$ & $34(26.8 \%)$ & 127 \\
\hline
\end{tabular}

$35.7 \%(10 / 28)$ of patients with a tumor diameter smaller than $2 \mathrm{~cm}$. miR-1260a expression level was increased in $65.7 \%(65 / 99)$, and was decreased in $34.3 \%(34 / 99)$ of patients with a tumor diameter larger than $2 \mathrm{~cm}$.
miR-1260b expression was increased in 71.4\% (20/28), and was decreased in $28.6 \%(8 / 28)$ of patients with a tumor diameter smaller than $2 \mathrm{~cm}$. The expression level was increased in $73.7 \%$ (73/99), and was decreased in 
$26.3 \%(26 / 99)$ of patients with a tumor diameter larger than $2 \mathrm{~cm}$ (Table 3 ).

The evaluation of ovarian cancer patients in accordance with their treatment type showed that miR-1260a expression level was increased in $63.9 \%$ (78/122), and was decreased in $36.1 \%$ (44/122) of patients who underwent surgery. miR-1260a expression level was increased in $100 \%(5 / 5)$, and no decrease was detected in expression levels of patients who did not undergo surgery. miR$1260 \mathrm{~b}$ expression level was increased in $71.3 \%$ (87/122), and was decreased in $28.7 \%(34 / 122)$ of patients who underwent surgery. miR-1260b expression level was increased in $100 \%(5 / 5)$, and no decrease was detected in expression levels of patients who did not undergo surgery (Table 3).

miR-1260a expression level was increased in $66.1 \%$ (78/118), and was decreased in $33.9 \%(40 / 118)$ of patients who underwent chemotherapy. miR1260a expression level was found to have increased in $50 \%$, and to have decreased in $50 \%$ of patients who received no chemotherapy. miR-1260b expression level was increased in $72.8 \%$ $(86 / 118)$, and was decreased in $27.2 \%(30 / 118)$ of patients who underwent chemotherapy. miR-1260b expression level was increased in $60 \%(6 / 10)$, and was decreased in $40 \%(4 / 10)$ of patients who received no chemotherapy (Table 3).

miR-1260a expression level was found to have increased in $66.6 \%(10 / 15)$, and to have decreased in $33.4 \%(5 / 15)$ of patients who received radiotherapy, however, miR1260a expression level was found to have increased in $65.1 \%(73 / 112)$, and to have decreased in $34.9 \%(39 / 112)$ of patients who received no radiotherapy. The miR-1260b expression level was found to have increased in $66.6 \%$ $(10 / 15)$, and to have decreased in $33.4 \%(5 / 15)$ of patients who received radiotherapy however, miR-1260b expression level was found to have increased in $73.2 \%$ (82/112), and to have decreased in $26.8 \%(29 / 112)$ of patients who received no radiotherapy (Table 3 ).

\section{Evaluation of the association between the miR-1260a, and miR-1260b expression levels, and family history} miR-1260a expression was detected to have decreased in $37.4 \%$ (31/83), and have increased in $62.6 \%(52 / 83)$ of patients with ovarian cancer and/or breast cancer patients in less than two individuals, miR-1260a expression was detected to have decreased in $29.6 \%(13 / 44)$, and have increased in $70.4 \%(31 / 44)$ of patients with 2 or more than 2 ovarian cancer and/or breast cancer patients in the family. miR-1260b expression was detected to have decreased in 29\% (24/83), and have increased in $71 \%$ $(59 / 83)$ of patients with ovarian cancer and/or breast cancer patients in less than two individuals in the family however, miR-1260b expression was detected to have decreased in $22.8 \%(10 / 44)$, and have increased in $77.2 \%$ (34/44) of patients with 2 or more than 2 ovarian cancer and/or breast cancer patients in the family.

\section{Evaluation of the miR-1260a, and miR-1260b Expression levels with the presence of BRCA1/BRCA2 Gene Mutations} miR-1260a expression was detected to have increased in $76 \%(19 / 25)$, and decreased in $24 \%(6 / 25)$ in BRCA positive ovarian cancer patients, and have increased in $62.7 \%$ (64/102), and decreased in 37.3\% (38/102) BRCA negative patients in the study.

miR-1260b expression was detected to have increased in $72 \%(18 / 25)$, and decreased in $28 \%(7 / 25)$ in BRCA positive ovarian cancer patients, and have increased in $73.5 \%$ (75/102), and decreased in 26.5\% (27/102) BRCA negative patients.

\section{Survival analysis}

The mean survival time of ovarian cancer patients in the present study was 103 months (SD $\pm 5.7 \mathrm{~m})$, and $45(35.4 \%)$ died, 78 (61.4\%) survived after diagnosis, and the situation of $4(3.2 \%)$ were unknown out of 127 patients that were screened between 2010-2019.

We performed the Kaplan-Meier Analysis to investigate whether miR-1260a, and miR-1260b expression levels were the variables affecting the survival time. No correlation was detected between the miR-1260a, and miR-1260b expression levels with the survival time (Table 4) (Fig. 3).

\section{ROC analysis}

We performed the Receiver Operator Characteristics (ROC) analysis for demonstrating the diagnostic performance of miR-1260a, and miR-1260b molecules as the candidate bioindicators - in other words their differentiation strength for ovarian cancer patient, and healthy control groups (Fig. 4). Table 5 demonstrates the ROC-AUC values, and 95\% CI (Confidence Interval) results identified for each miRNA, and these results showed that the

Table 4 Correlations Between miRNAs Expression Levels, and Survival

\begin{tabular}{lllll}
\hline miR-1260a Expression & Total N & N of Events & \multicolumn{2}{c}{ Censored } \\
\cline { 4 - 5 } & & & $\mathbf{N}$ & Percent \\
\hline Decreased & 44 & 26 & 18 & $40.9 \%$ \\
Increased & 83 & 52 & 31 & $37.3 \%$ \\
Ovarian all & 127 & 78 & 49 & $38.6 \%$ \\
miR-1260b Expression & & & & \\
Decreased & 34 & 20 & 14 & $41.2 \%$ \\
Increased & 93 & 58 & 35 & $37.6 \%$ \\
Ovarian all & 127 & 78 & 49 & $38.6 \%$ \\
\hline
\end{tabular}



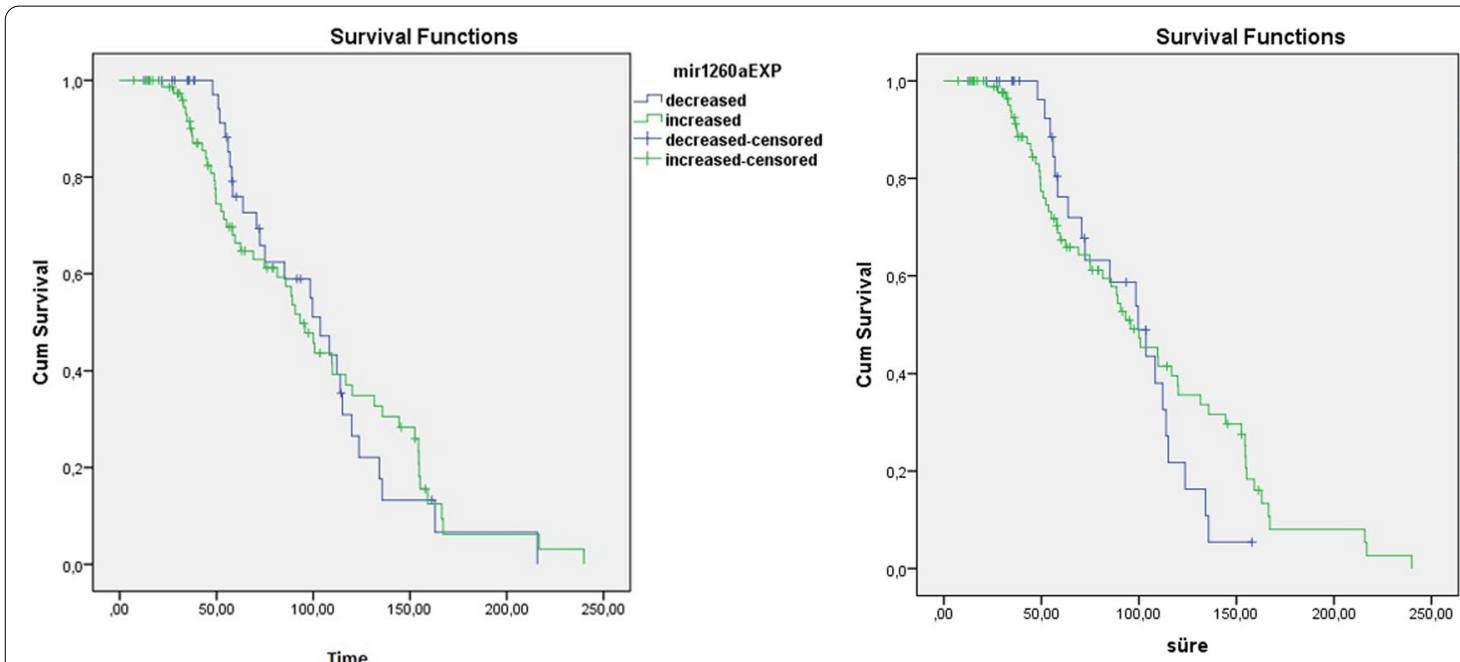

mir1260bEXP

decreased

-

increased-censored

Fig. 3 Survival Analysis for both miR-1260a, and miR-1260b

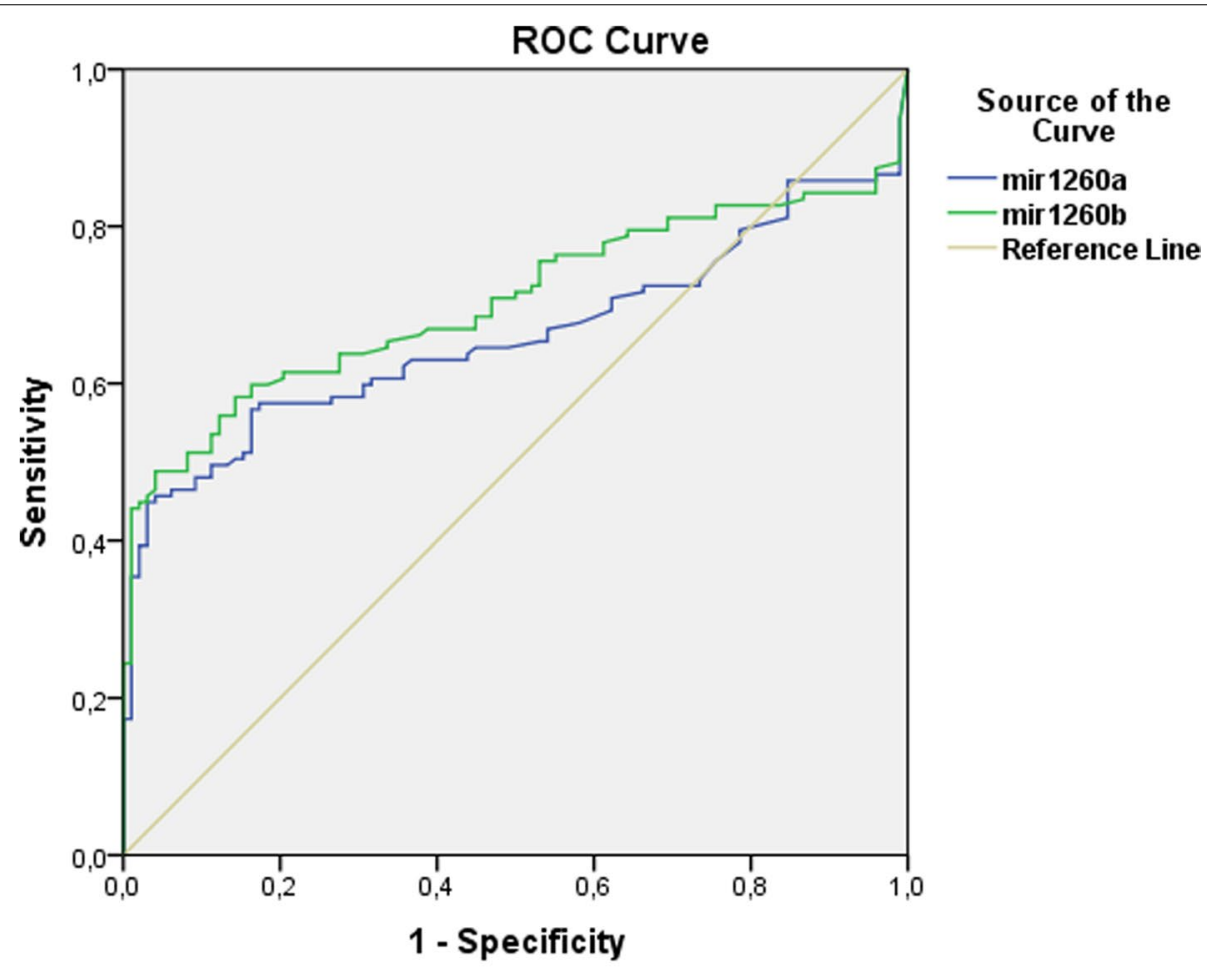

Diagonal segments are produced by ties.

Fig. 4 Graph of ROC-AUC values of miRNAs in separation of ovarian cancer patients and healthy groups. Blue line: miR-1260a; Green line: miR-1269b

diagnostic strength of miR-1260a, and miR-1260b molecules were statistically significant in the diagnosis of ovarian cancer patients (p:0.000).
Correlation between CA-125 value, and the expression level of miRNAs

We performed the "Spearman's correlation analysis" for identifying whether there was a linear assocation 
Table 5 ROC-AUC Values of miRNAs in the Separation of Ovarian Cancer Patients, and Healthy Groups

\begin{tabular}{llll}
\hline miRNAs & ROC-AUC & $\mathbf{9 5 \% ~ C l}$ & p value \\
\hline miR-1260a & 0.660 & $0.588-0.733$ & .000 \\
miR-1260b & 0.704 & $0.635-0.773$ & .000 \\
\hline
\end{tabular}

Table 6 Correlation Statistics Between miRNA Expression levels, and CA-125 Variables

\begin{tabular}{lll}
\hline p Values & $\begin{array}{l}\text { CA-125 value on } \\
\text { diagnosis }\end{array}$ & $\begin{array}{l}\text { CA-125 } \\
\text { value after } \\
\text { treatment }\end{array}$ \\
\hline miR-1260a & 0.076 & 0.263 \\
miR-1260b & 0.094 & 0.122 \\
\hline
\end{tabular}

between the numerical measurements of miR-1260a, and miR-1260b expression levels with the CA-125 values obtained from the clinical data of the ovarian cancer patients. There was no correlation, and no statistical significance between the miR-1260a, and miR-1260b expression levels with the Ca-125 numerical variables controlled in the beginning of treatment, and during treatment $(\mathrm{p}>0.05)$ (Table 6).

\section{String analysis for identifying the Gene/Proteins that the miR-1260a, and miR-1260b were interacted}

An experimental gene list was created for miR-1260a, and miR-1260b using the miRTarBase data bank. The estimated target genes for miR-1260a, and miR-1260b were identified using the TargetScan database. The cumulative gene targets smaller than zero for each miRNA were identified using the TargetScan. Accordingly, 4857 gene target for hsa-miR-1260a , and 388 gene targets for hsamiR-1260b were detected. Then, the gene targets identified by TargetScan were compared with gene target lists identified by miRTarBase, and the common gene count for miR1260a was reduced to 42 Target Genes, and to 8 Target Genes for miR-1260b. The common gene targets detected for miR1260a by miRTarBase, and TargetScan were identified to have significant interactions in protein level after analysis performed using the String database (p:0.000). The results of the analysis, and the interacting genes are shown in Fig. 5.

The String Analysis showed that the most important protein family that the miR-1260a was associated was the ribosomal protein family which was known to be effective in the cellular stage of translation. Some studies in the literature investigated the effects of this protein family on the development of ovarian cancer [36, 37]. These studies showed that ribosomal proteins had significant, and critical functions in the development of ovary, and therefore may provide data about the pathophysiology, and treatment of ovarian dysfunctions.

The common gene targets which were detected from miRTarBase, and TargetScan for miR1260b were found to have interaction in protein level after analysis performed using the String database (p:0.00361). The interacting genes are shown in Fig. 6.

The String analysis showed that the most important protein that miR-1260b was associated was the CHEK2 protein which was a member of the serine/threonineprotein kinase family. This protein has a significant role in inhibiting the control points in cell cycle, and in the activation of DNA repair. One another important protein was the CDK4 protein which was one of the members of cycline dependent kinase family. The abnormal activation of this protein has a role in the proliferation, and apoptosis of ovarian cancer cells. The cyclines functioning as the CDK kinase regulators (CCND2, CCNB1) were also striking. Cycline proteins were reported to be expressed in high levels in ovarian cancer tissues [7].

\section{Discussion}

Approximately 22.240 individuals were diagnosed with ovarian cancer in 2018 in the USA. 14.070 of the diagnosed individuals were reported to have died of ovarian cancer [38]. 2018 Globocan data showed that 7 individuals in every 100.000 were diagnosed with ovarian cancer in Turkey. The age-adjusted highest incidence ratios were generally higher than 8 in 100.000 in developed regions including the North America, Central, and East Europe. The ratios were reported as 5.8 in 100.000 in South America, and as $\leq 3$ in 100.000 in Asia, and Africa $[5,39]$. Ovarian cancer is the most common gynecologic tumors with the highest mortality rate. The epidemiologic studies showed that hormonal, and reproductive factors were effective in cancer pathogenesis [40]. Ovarian carcinoma involves genetic, and epigenetic changes causing cell transformation. Although significant data has been obtained about the ovarian cancer oncogenes in the last decade, there is no clear data about the etiology. Various studies showed that miRNAs had significant role in various diseases including cancer, and stated that may be used as molecular biologic indicator and even as molecular target for cancer treatment or these miRNAs might be used as chemotherapeutic agent. Ovarian cancer needs to be investigated as the disease etiology is not clearly known, and there is no available biologic indicators for the use in the early diagnosis, and treatment of the disease. Therefore, it is important to search, and 


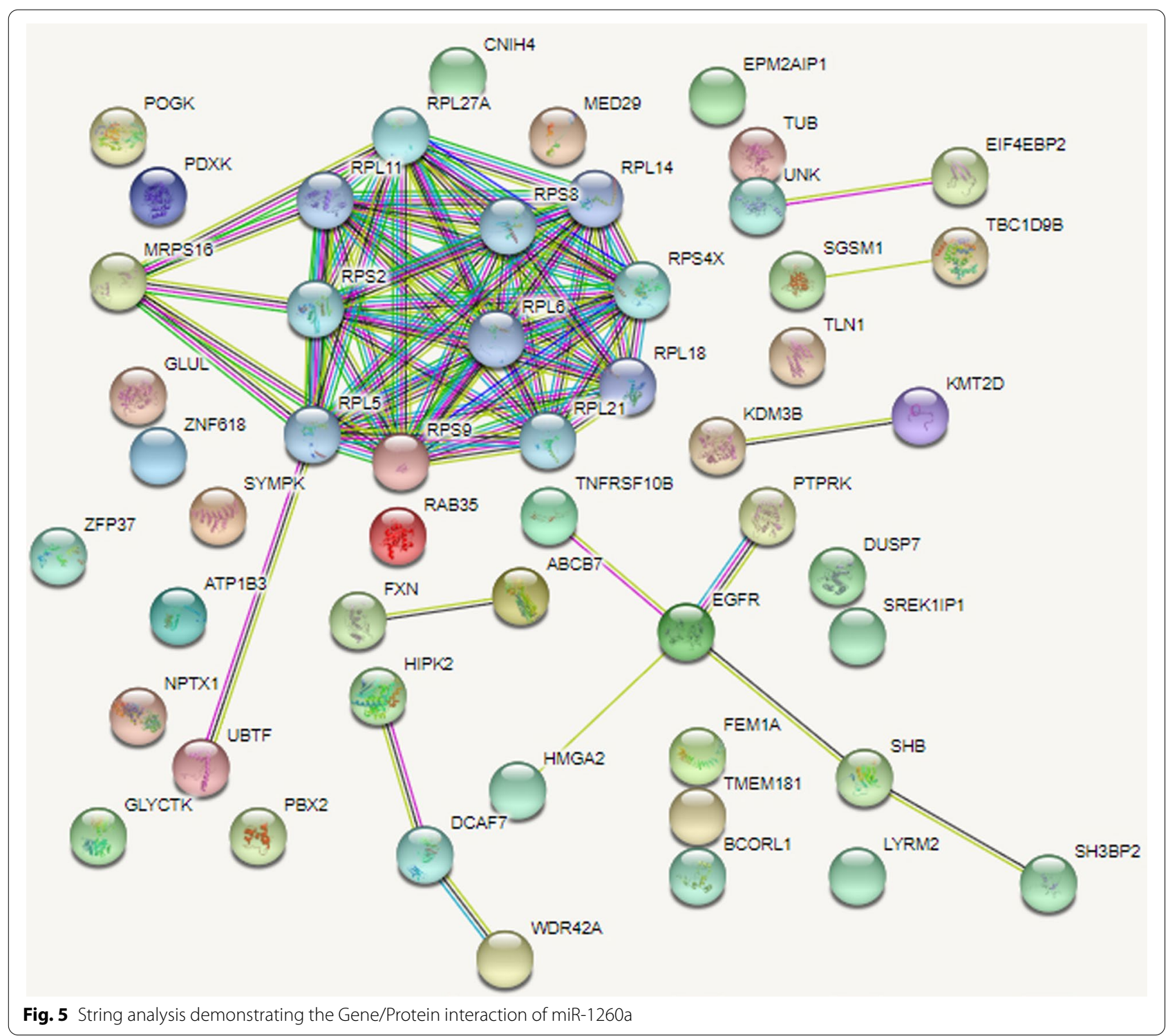

investigate for new biologic indciators to be described for this disease.

Many miRNA molecules associated with the development, diagnosis, and treatment of ovarian cancer have been investigated so far. The expression levels of miR193b, miR-532, and miR-3064 were reported to be associated with the FIGO staging used in ovarian cancer staging, tumor diameter, histologic grade, ascitis accumulation, lymph node metastasis, and with the poor prognosis $[41,42]$. However, miR-506 was shown to be associated with early FIGO Staging, and good prognosis and long time survival [43]. miR-199 was reported to have lower expression in ovarian cancer, and this miRNA inhibited the related gene pathway by blocking the activation of the c-MET, HIF1-alpha HIF2-beta, and IKK-beta proteins, and thus might be a therapeutic target [44-46]. miR-152 was shown to suppress the proliferation, and metastatis abilities of ovarian cancer cells by suppressing the ERBB3 expression in ovarian cancer cell strains. Therefore, miR-152 was reported as a possible significant molecular target in cell proliferation, invasion, and metastasis of ovarian cancer [47].

Different researchers reported various miRNAs which caused the development of resistance against ovarian cancer treatment [Jin, 2018 \#570]. let-7 [48] , miR-9, miR-366, miR-424 [49], and miR-622 [50] were counted among these miRNAs. miRNAs circulating in the exosomal, and peripheral blood in the diagnosis and follow up of ovarian cancer were also reported. miR-21, miR-141, miR-200a, miR-200c, miR-200b, miR-203, miR-205, and 


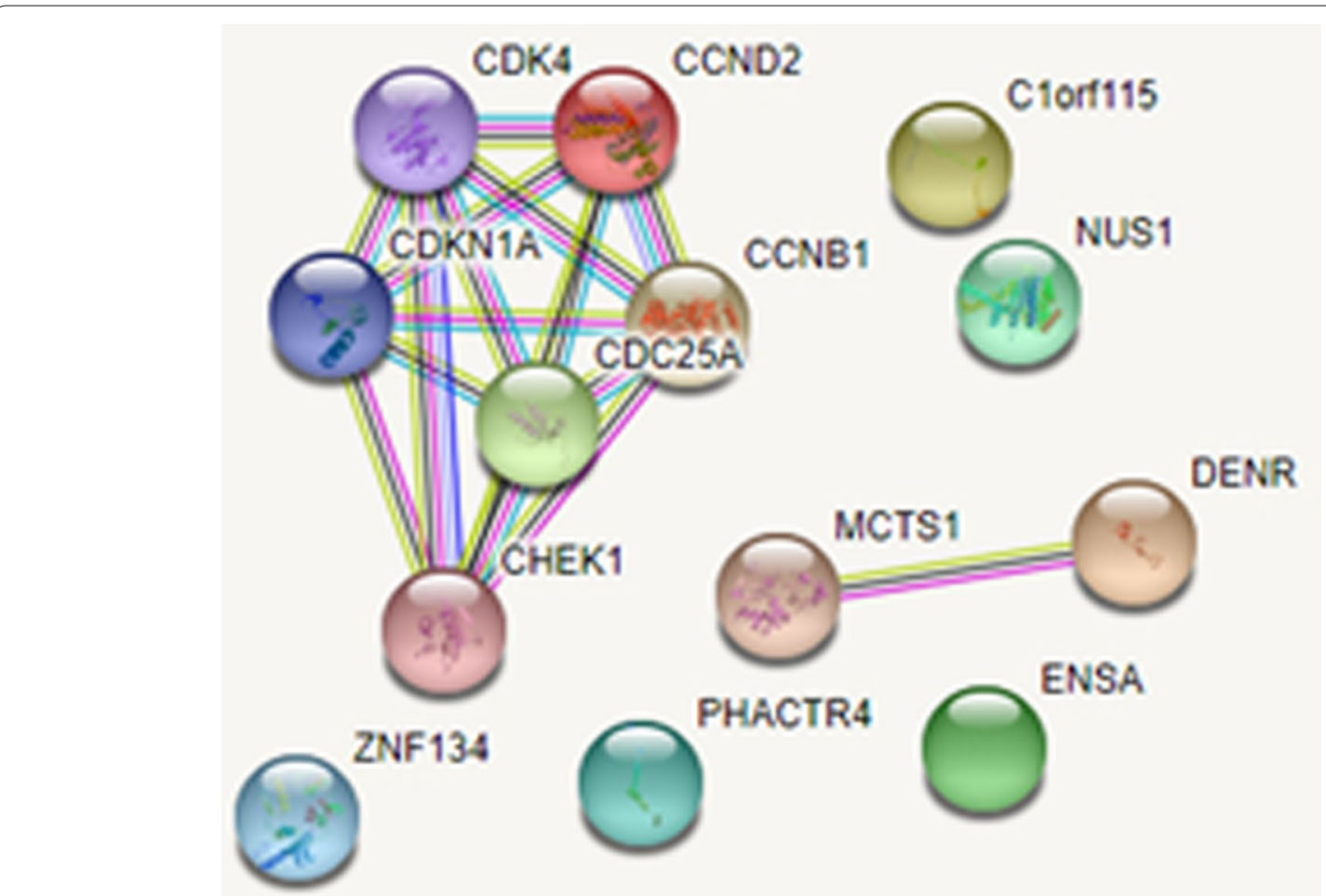

Fig. 6 String analysis demonstrating the Gene/Protein interaction of miR-1260b

miR-214 were found as exosomal in serum, and were correlated with the advanced stage ovarian cancer, and miR106b, miR-126, miR-150, miR-17, miR-20a, and miR-92a found in plasma were shown to be possibly used in the differentiation of benign ovarian disease from malignant ovarian diseases [51]. The miR-92a, and miR-200b expression levels were detected to have differentiated in the ascitis fluid generated by ovarian cancer cells, and in the urines of patients compared with the healthy controls [52]. miR-630, and miR-205 expression differences in the invasion of the ovarian cancer cells were shown to be associated with the invasive behavior of the ovarian cancer patients [53]. miR-125 was found to be effective in miR-200 family, and miR-30d miRNA genes were effective in the epithelial mesenchymal transition (EMT) [54-57]. Researchers reported that miR-222-3p expression in ovarian cancer was associated with long time survival; the lower expression of miR-9, miR-595(81), and miR-15b with higher expression of WNT7a [58] were associated with shorter survival, and poor prognosis, in addition, the differences in the expression levels of miR14 159], miR-200a, and miR-200c were reported to be associated with the progression-free survival (PFS). The PubMed screening until 2018 various above mentioned miRNAs were investigated in ovarian cancer, and were associated with ovarian cancer diagnosis, prognosis, survival, drug resistance, and metastatic characteristics.

There is no study in the literature investigating the role of miR-1260a, and miR-1260b miRNA molecules in ovarian cancer. The expression level of miR-1260a was investigated in breast, kidney, gastric cancer, malignant melanoma, hepatocellular carcinoma, colorectal carcinoma, and esophageal squamous cell carcinoma, and was detected to have been upregulated in these cancers [22-29]. In addition, miR-1260a expression level was reported to have high level expression in the serum, and FFPE tissues of prostate cancer patients compared with the BPH controls, and higher expression was also reported in prostate cell strains [30, 31, 60]. miR-1260a expression level was shown to have upregulated in prostate cancer patients compared with the $\mathrm{BPH}$ controls [60]. miR-1260a was reported as one of the 13 miRNAs with diagnostic biologic indicator property used in the classification of the FFPE of prostate cancer patients in Denmark population [30, 34].

The miR-1260b was also reported to have been investigated in various cancer types except ovarian cancer in the literature, and was associated with cancer, and showed abnormal expression. miR-1260b was reported to have been abnormally, and highly expressed in the dendritic cells in human peripheral blood, and therefore 
was suggested to be associated with immune response [33]. miR-1260b expression level was suggested to have increased in colorectal cancer tissues particularly with lymph node metastasis, and this was suggested to be associated with lymph node metastasis, and venous invasion, and showed the early stage metastasis. miR-1260b was suggested to be an important molecular biologic indicator in CRC prognosis [61]. In addition, miR-1260b was investigated in malignant melanoma patients, and miR-1260a was reported to show a different expression pattern in the surgical resection follow up of melanoma [62]. mi1260a expression was shown to have higher expression in atypical Spitz lesions compared with the levels in benign Spitz tumors [63]. mi1260b was detected to decrease the cell migration, and invasion in nonsmall cell lung cancer cell strains (A549). This results suggest that miR-1260b had an important role in inhibiting the metastasis in NSCLC patients, and might be a target molecule in NSCLC treatment [64].

Researchers showed that miR-1260b had extremely higher expression in renal cell cancer cells compared with the levels in normal kidney cells, and this expression was correlated with cell proliferation, invasion, and shorter survival, and miR-1260 showed this effect by inhibiting the Wnt signal pathway in these incidents [65].

The comparison of the ovarian cancer patients, and healthy control group with the analysis results in the present study showed that there was a highly significant difference ( $\mathrm{p}: 0.000)$. miR-1260a, and miR-1260b expressions were found to have increased between 16.1-45.08 fold in ovarian cancer patients compared with the healthy controls. The String analysis showed that miR-1260a was mostly associated with the ribosomal protein family effective in translation. There are some studies in the literature investigating the effects of this protein family of the development of ovarian cancer [36, 37]. The results of this studies showed that the ribosomal proteins had significant and critical functions in the development of ovarian cancer, and therefore was emphasized to provide information on the pathophysiology, and treatment of ovarian dysfunctions. The evaluation of all these data showed that the deteriorations developing in the ribosomal proteins of ovarian cancer might also be indirectly generated.

String Analysis performed for miR1260b showed that miR-1260b had a close association with 'Serin/Treoninprotein kinase family member of CHEK2 protein, and cycline dependent kinase family members of CDK4 protein. One of which is effective in DNA repair, and the other is effective in cell proliferation, and apoptosis control suggesting that these genes contributed to tumor development by inhibiting the cell proliferation, and apoptosis in ovarian cancer development [7]. All these results may conclude that the interaction of 2 different gene families with miR1260 may cause the development of ovarian cancer. These results should be investigated in future studies.

\section{Conclusion}

In summary, the significant expression of miR1260, and miR1260b in the peripheral blood lymphocytes of ovarian cancer patients compared with the healthy controls was first demonstrated by our group, the gene interactions of these two genes are suggested to have diagnostic significance owing to causing ovarian cancer. In addition, the present study suggests that miR1260a, and miR1260b molecules which were detected to have differentiated particularly in peripheral blood had prognostic significance, and therefore might be used as bioindicators. These molecules must also be investigated in the benign ovarian diseases for better understanding their importance in the early diagnosis, and diagnostic importance in ovarian cancer. In addition, the comparative investigation of the levels of these molecules in the peripheral blood during treatment is required to be studied for identifying their safety as prognostic biologic indicator.

\section{Acknowledgements \\ Thanks to the technicians who were Arzu Bornova and Turkan Şen Ferhadoğlu for assistance and laboratory organizations.}

\section{Authors' contributions}

PS recruited and referred patients to the study. AAG performed the experiments and help writing the manuscript. SBT and DAO performed statistical analysis. All experiments were required in the laboratory of HY. All the chemicals and KITs required for the experimental processes of the study was provided by HY. HY also wrote the manuscript, contributed towards the interpretation of data, writing of the manuscript and increased the scientific value of writing adding intellectual information. BK and MAS recruited healthy cases to the study and also collected the data and drawing pedigrees and fill up demographic information forms and prepared all documents for the samples. OSE and SKE performed STRING analysis. BC criticized the manuscript according to literature intellectually. All authors read and approved the final manuscript.

\section{Funding}

This work was supported by Scientific Research Projects Coordination Unit of Istanbul University (Project number: TYL-2018-31188).

\section{Availability of data and materials}

The datasets used and/or analyzed during the current study are available from the corresponding author on reasonable request.

\section{Declarations}

Ethics approval and consent to participate

The study was approved by the Local and Clinical Research Ethics Committee of Istanbul University (Number of ethical approval: 2018712); according to the tenets of the Declaration of Helsinki. Written informed consent was obtained from all participants.

Competing interests

The authors declare that they have no competing interests. 


\section{Author details}

'Division of Cancer Genetics, Department of Basic Oncology, Oncology Institute, Istanbul University, Fatih, 34093 Istanbul, Turkey. ${ }^{2}$ Health Science Institute, Istanbul University, Fatih, 34093 Istanbul, Turkey. ${ }^{3}$ Health Services Vocational School of Higher Education, T.C. Istanbul Aydin University, Sefakoy, Kucukcekmece, 34295 Istanbul, Turkey. ${ }^{4}$ Department of Medical Oncology, Oncology Institute, Istanbul University, Fatih, 34093 Istanbul, Turkey. ${ }^{5}$ Medical Biology and Genetics Department, Medical Faculty, Istanbul Arel University, Istanbul, Zeytiburnu 34010, Turkey.

\section{Received: 16 September 2020 Accepted: 8 September 2021}

\section{Published online: 10 October 2021}

\section{References}

1. Miller KD, et al. Cancer Statistics for Hispanics/Latinos, 2018. CA Cancer J Clin. 2018;68(6):425-45.

2. Crawford MH, et al. ACC/AHA Guidelines for Ambulatory Electrocardiography. A report of the American College of Cardiology/American Heart Association Task Force on Practice Guidelines (Committee to Revise the Guidelines for Ambulatory Electrocardiography). Developed in collaboration with the North American Society for Pacing and Electrophysiology. J Am Coll Cardiol. 1999:34(3):912-48.

3. Patbol, A.J., 177:1053-1064; https://doi.org/10.2353/ajpatb.2010.100105. 2010.

4. Kliewer EV, Smith KR. Ovarian cancer mortality among immigrants in Australia and Canada. Cancer Epidemiol Biomarkers Prev. 1995;4(5):453-8.

5. Wei K, et al. Ovary cancer incidence and mortality in China, 2011. Chin J Cancer Res. 2015;27(1):38-43.

6. https://www.genecards.org/cgi-bin/carddisp.pl?gene=CHEK2\&keywo $\mathrm{rds}=\mathrm{CHEK} 2$.

7. Zhang $\mathrm{R}$, et al. The aberrant upstream pathway regulations of CDK1 protein were implicated in the proliferation and apoptosis of ovarian cancer cells. J Ovarian Res. 2017;10(1):60.

8. Boyd C, McCluggage WG. Low-grade ovarian serous neoplasms (lowgrade serous carcinoma and serous borderline tumor) associated with high-grade serous carcinoma or undifferentiated carcinoma: report of a series of cases of an unusual phenomenon. Am J Surg Pathol. 2012:36(3):368-75.

9. Diaz-Padilla I, et al. Ovarian low-grade serous carcinoma: a comprehensive update. Gynecol Oncol. 2012;126(2):279-85.

10. Gershenson DM, et al. Recurrent low-grade serous ovarian carcinoma is relatively chemoresistant. Gynecol Oncol. 2009;114(1):48-52.

11. Gershenson DM, et al. Clinical behavior of stage II-IV low-grade serous carcinoma of the ovary. Obstet Gynecol. 2006;108(2):361-8.

12. Antoniou $A$, et al. Average risks of breast and ovarian cancer associated with BRCA1 or BRCA2 mutations detected in case Series unselected for family history: a combined analysis of 22 studies. Am J Hum Genet. 2003;72(5):1117-30.

13. Chen S, Parmigiani G. Meta-analysis of BRCA1 and BRCA2 penetrance. J Clin Oncol. 2007;25(11):1329-33.

14. Lee RC, Feinbaum RL, Ambros V. The C. elegans heterochronic gene lin-4 encodes small RNAs with antisense complementarity to lin-14. Cell. 1993;75(5):843-54.

15. Reinhart BJ, et al. The 21-nucleotide let-7 RNA regulates developmental timing in Caenorhabditis elegans. Nature. 2000;403(6772):901-6.

16. Kozomara A, Griffiths-Jones S. miRBase: integrating microRNA annotation and deep-sequencing data. Nucleic Acids Res. 2011;39(Database issue):D152-7.

17. Lee $Y$, et al. MicroRNA genes are transcribed by RNA polymerase II. EMBO J. 2004;23(20):4051-60.

18. Cai $X$, Hagedorn $\mathrm{CH}$, Cullen BR. Human microRNAs are processed from capped, polyadenylated transcripts that can also function as mRNAs. RNA. 2004;10(12):1957-66.

19. Borchert GM, Lanier W, Davidson BL. RNA polymerase III transcribes human microRNAs. Nat Struct Mol Biol. 2006;13(12):1097-101.

20. Calin GA, et al. Frequent deletions and down-regulation of micro- RNA genes miR15 and miR16 at 13q14 in chronic lymphocytic leukemia. Proc Natl Acad Sci U S A. 2002;99(24):15524-9.
21. Madhavan D, et al. Circulating miRNAs with prognostic value in metastatic breast cancer and for early detection of metastasis. Carcinogenesis. 2016;37(5):461-70.

22. Sand $M$, et al. Comparative microarray analysis of microRNA expression profiles in primary cutaneous malignant melanoma, cutaneous malignant melanoma metastases, and benign melanocytic nevi. Cell Tissue Res. 2013;351(1):85-98.

23. Yan $\mathrm{H}$, et al. Molecular pathways and functional analysis of miRNA expression associated with paclitaxel-induced apoptosis in hepatocellular carcinoma cells. Pharmacology. 2013;92(3-4):167-74.

24. Zheng $\mathrm{G}$, et al. Serum microRNA panel as biomarkers for early diagnosis of colorectal adenocarcinoma. Br J Cancer. 2014;111(10):1985-92.

25. Dai F, et al. The global expression profiling in esophageal squamous cell carcinoma. Genomics. 2017:109(3-4):241-50.

26. Yoshino $\mathrm{H}$, et al. Downregulation of microRNA-1274a induces cell apoptosis through regulation of BMPR1B in clear cell renal cell carcinoma. Oncol Rep. 2018;39(1):173-81.

27. Halvorsen AR, et al. Evaluation of Prognostic and Predictive Significance of Circulating MicroRNAs in Ovarian Cancer Patients. Dis Markers. 2017:2017:3098542.

28. Wang GJ, et al. The role of microRNA-1274a in the tumorigenesis of gastric cancer: accelerating cancer cell proliferation and migration via directly targeting FOXO4. Biochem Biophys Res Commun. 2015;459(4):629-35

29. Kristensen $\mathrm{H}$, et al. Novel diagnostic and prognostic classifiers for prostate cancer identified by genome-wide microRNA profiling. Oncotarget. 2016:7(21):30760-71.

30. Moltzahn F, et al. Microfluidic-based multiplex qRT-PCR identifies diagnostic and prognostic microRNA signatures in the sera of prostate cancer patients. Cancer Res. 2011;71(2):550-60.

31. Hessvik NP, et al. Profiling of microRNAs in exosomes released from PC-3 prostate cancer cells. Biochim Biophys Acta. 2012;1819(11-12):1154-63.

32. Jing Li LL, Limin $X$, et al. Expression of microRNA-1260b in nonsmallcell lung carcinoma and the clinical significance. Chin J Exp Surg. 2015:32(3):624-6.

33. Hirata $\mathrm{H}$, et al. Genistein downregulates onco-miR-1260b and upregulates SFRP1 and Smad4 via demethylation and histone modification in prostate cancer cells. Br J Cancer. 2014;110(6):1645-54.

34. Liu DR, Guan QL, Gao MT, Jiang L, Kang HX. miR-1260b is a Potential Prognostic Biomarker in Colorectal Cancer, Med Sci Monit. 2016;22:2417-23. https://doi.org/10.12659/MSM.898733.

35. Livak KJ, Schmittgen TD. Analysis of relative gene expression data using real-time quantitative PCR and the 2(-Delta Delta C(T)) Method. Methods. 2001;25(4):402-8

36. Liu XM, et al. Loss of oocyte Rps26 in mice arrests oocyte growth and causes premature ovarian failure. Cell Death Dis. 2018:9(12):1144.

37. Chen A, et al. Mutations in the mitochondrial ribosomal protein MRPS22 lead to primary ovarian insufficiency. Hum Mol Genet. 2018;27(11):1913-26.

38. Bray F, et al. Global cancer statistics 2018: GLOBOCAN estimates of incidence and mortality worldwide for 36 cancers in 185 countries. CA Cancer J Clin. 2018;68(6):394-424

39. Allemani C, et al. Global surveillance of cancer survival 1995-2009: analysis of individual data for 25,676,887 patients from 279 population-based registries in 67 countries (CONCORD-2). Lancet. 2015;385(9972):977-1010.

40. Tung $\mathrm{KH}$, et al. Effect of anovulation factors on pre- and postmenopausal ovarian cancer risk: revisiting the incessant ovulation hypothesis. Am J Epidemiol. 2005:161(4):321-9.

41. Yazici H. eBook: Current Trends in Cancer Management (ISBN:9781-83880-006-2); Chapter: Functions of miRNAs in the Development, Diagnosis, and Treatment of Ovarian Carcinoma. Eds: Streba L, Gheonea DI, Schenker M. 2019. https://doi.org/10.5772/Intechopen.85100.

42. Li H, et al. Tissue miR-193b as a Novel Biomarker for Patients with Ovarian Cancer. Med Sci Monit. 2015;21:3929-34.

43. Sun Y, et al. MiR-506 inhibits multiple targets in the epithelial-to-mesenchymal transition network and is associated with good prognosis in epithelial ovarian cancer. J Pathol. 2015;235(1):25-36.

44. Kinose Y, Sawada K, Nakamura K, Sawada I, Toda A, Nakatsuka E, Hashimoto K, Mabuchi S, Takahashi K, Kurachi H, Lengyel E, Kimura T. The hypoxia-related microRNA miR-199a-3pdisplays tumor suppressor functions in ovarian carcinoma.Oncotarget. 2015;6(13):11342-56. https://doi. org/10.18632/oncotarget.36042015. 
45. Joshi HP, et al. Dynamin 2 along with microRNA-199a reciprocally regulate hypoxia-inducible factors and ovarian cancer metastasis. Proc Natl Acad Sci U S A. 2014;111(14):5331-6.

46. Chen R, et al. Regulation of IKKbeta by miR-199a affects NF-kappaB activity in ovarian cancer cells. Oncogene. 2008;27(34):4712-23.

47. Li LW, Xiao HQ, Ma R, Yang M, LiW, Lou G. miR-152 is involved in the proliferation and metastasis of ovarian cancer through repression of ERBB3. Int J Mol Med. 2018;41(3):1529-35. 2017. https://doi.org/10.3892/ijmm.2017.3324.

48. Iorio MV, Croce CM. Commentary on microRNA Fingerprint in Human Epithelial Ovarian Cancer. Cancer Res. 2016;76(21):6143-5.

49. Xu S, Tao Z, Hai B, Liang H, Shi Y, Wang T, Song W, Chen Y, OuYang J, Chen J, Kong F, Dong Y, Jiang SW, Li W, Wang P, Yuan Z, Wan X, Wang C, Li W, Zhang X, Chen K. miR-424(322) reverses chemoresistance via T-cell immune response activation by blocking the PD-L1 immune checkpoint Nat Commun. 2016;7:11406. https://doi.org/10.1038/ncomms11406.

50. Choi YE, et al. Platinum and PARP Inhibitor Resistance Due to Overexpression of MicroRNA-622 in BRCA1-Mutant Ovarian Cancer. Cell Rep. 2016;14(3):429-39.

51. Shapira I, et al. Circulating biomarkers for detection of ovarian cancer and predicting cancer outcomes. Br J Cancer. 2014;110(4):976-83.

52. Zavesky L, et al. Evaluation of Cell-Free Urine microRNAs Expression for the Use in Diagnosis of Ovarian and Endometrial Cancers. A Pilot Study. Pathol Oncol Res. 2015;21(4):1027-35.

53. Wei J, et al. MicroRNA-205 promotes cell invasion by repressing TCF21 in human ovarian cancer. J Ovarian Res. 2017;10(1):33.

54. Cowden Dahl KD, et al. The epidermal growth factor receptor responsive miR-125a represses mesenchymal morphology in ovarian cancer cells. Neoplasia. 2009;11(11):1208-15.

55. Ying $X$, et al. MicroRNA-125b Suppresses Ovarian Cancer Progression via Suppression of the Epithelial-Mesenchymal Transition Pathway by Targeting the SET Protein. Cell Physiol Biochem. 2016;39(2):501-10.

56. Park SM, et al. The miR-200 family determines the epithelial phenotype of cancer cells by targeting the E-cadherin repressors ZEB1 and ZEB2. Genes Dev. 2008;22(7):894-907.
57. Ye Z, et al. TET3 inhibits TGF-beta1-induced epithelial-mesenchymal transition by demethylating miR-30d precursor gene in ovarian cancer cells. J Exp Clin Cancer Res. 2016;35:72.

58. MacLean JA 2nd, et al. WNT7A Regulation by miR-15b in Ovarian Cancer. PLoS One. 2016;11(5):e0156109.

59. Shi M, Mu Y, Zhang H, Liu M, Wan J, Qin X, Li C. MicroRNA-200 and microRNA-30 family as prognostic molecular signatures in ovarian cancer: a meta-analysis. Medicine (Baltimore). 2018;97(32):e11505. https://doi.org/ 10.1097/MD.0000000000011505.

60. Cherni I, Weiss GJ. miRNAs in lung cancer: large roles for small players. Future Oncol. 2011;7(9):1045-55.

61. Krutzfeldt J, et al. Specificity, duplex degradation and subcellular localization of antagomirs. Nucleic Acids Res. 2007;35(9):2885-92.

62. Latchana N, DiVincenzo MJ, Regan K, AbramsZ, ZhangX, Jacob NK, Gru AA, Fadda P, Markowitz J, Howard JH, Carson WE III. Alterations in patient plasma microRNA expression profiles following resection of metastatic melanoma. J Surg Oncol. 2018;118(3):501-9. https://doi.org/10.1002/jso.25163.

63. Latchana $\mathrm{N}$, et al. Global microRNA profiling for diagnostic appraisal of melanocytic Spitz tumors. J Surg Res. 2016;205(2):350-8.

64. $\mathrm{Xu} \mathrm{L}$, et al. MiR-1260b promotes the migration and invasion in non-small cell lung cancer via targeting PTPRK. Pathol Res Pract. 2018;214(5):776-83.

65. Hirata $\mathrm{H}$, et al. Correction: Genistein downregulates onco-miR-1260b and upregulates SFRP1 and Smad4 via demethylation and histone modification in prostate cancer cells. Br J Cancer. 2018;119(3):388.

\section{Publisher's Note}

Springer Nature remains neutral with regard to jurisdictional claims in published maps and institutional affiliations.
Ready to submit your research? Choose BMC and benefit from:

- fast, convenient online submission

- thorough peer review by experienced researchers in your field

- rapid publication on acceptance

- support for research data, including large and complex data types

- gold Open Access which fosters wider collaboration and increased citations

- maximum visibility for your research: over $100 \mathrm{M}$ website views per year

At BMC, research is always in progress.

Learn more biomedcentral.com/submissions 